187

VITAMIN E, PREGNANCY DURATION AND QUALITY OF LABOR Lois $H$. Johnson, Mirtes $V$. Beirao, Dorothy K. Neff, Charles B. Fenster, Dennis E. Martel. Univ. of Penna Sch. of Med. Penna. Hospital, Dept. Pediatrics, Phila. Penna. There is increasing evidence that Vitamin $E$ regulates prosta$g l$ and in synthes is. This suggests a mechanism for the many anecdotal reports of benefit from $R x$ with Vitamin $E$ in cases of infertility and abortion. Results of preliminary studies in rats with timed pregnancies ( $9 \mathrm{hr}$ mating exposure-vaginal plug pregnancy criterion), as modified by the administration of high doses of oral and parenteral Vitamin E from days 16 to 21 , are reported. of oral and parenteral no $\mathrm{E}$. Normal gestation in rats lasts 22.0 days. In $16 \mathrm{E}$ rats, mean gestation was prolonged by $7.5 \mathrm{hrs}$ over that of 13 control rats $(22$ days -8.5 hrs versus 22 days $-1 \mathrm{hr}$ ). This is equivalent to a 4.5 day delay in terms of a 40 week gestation. 2 instances of prolonged labor in $E$ Rx rats were observed. Gestation in $2 \mathrm{E}$ Rx rats was extended to 23.0 days with out evidence of toxicity. In 2 other E Rx rats, 7 and 10 pups were born after gestations of 23 days $-6 \mathrm{hrs} \& 23$ days $-10 \mathrm{hrs}$ respectively. Both litters were of poor viability. 4 pups were nearly dead at delivery. Several others were pale and apneic. The right side of the heart was strikingly distended in one mori bund pup. All other litters from E Rx rats were vigorous and com pletely comparable to controls. Sera for progesterone \& prostaglandin analyses were collected. E levels in E Rx rats ranged from 3.5 to $6.0 \mathrm{mg} \%$. In control rats the serum $E$ level tended to fall off one to two days before delivery, which may have physiologic significance. \section{THE PRENATAL TRIIODOTHYRONINE (T3) SURGE IN THE FETAL}

188 SHEEP. A. H. Klein, T.H. Oddie and D.A. Fisher, Fetal-Maternal Resear

General Hospital, Torrance, CA.

Thomas, et al, reported an increase in fetal T3 concentrations during cortisol induced premature labor in sheep. The present study characterizes changes in Thyroxine (T4), T3, and
reverse $\mathrm{T} 3$ ( $\mathrm{T}$ T3) concentrations during the 2 week period prior to spontaneous vaginal delivery (PTD) and during the immediate neonatal period in the sheep. Serial blood samples were collected from 5 chronically catheterized fetal sheep during the 2 weeks PTD. All 5 fetuses were live born. Serum was analyzed for T4, T3, and rT3 by radioimmunoassay. Serum T3 began to in crease $4-6$ days PTD from a stable geometric mean of $30 \mathrm{ng} / \mathrm{dl}$
(upper $95 \%$ confidence 1 imit $=39 \mathrm{ng} / \mathrm{dl}$ ) to a geometric mean of $131 \mathrm{ng} / \mathrm{dl}$ (lower $95 \%$ conf idence limit $=100 \mathrm{ng} / \mathrm{dl}$ ) on the day of delivery (Day 0$)$. Serum T4 decreased in 4 of the animals and remained unchanged in $l$ du ing this time interval. Serum Day 0. The fetal serum T3/T4 ratio increased markedly during the week PTD. Serum T3 levels increased further after delivery a mean level of $487 \mathrm{ng} / \mathrm{dl}$ was measured in 3 lambs at $2-4$ hours
of age. Conclusions: a) fetal serum $T 3$ levels gradualiy increase while $\mathrm{T} 4$ and $\mathrm{r} T 3$ concentrations decrease during the 4-6 crease while T4 and $r T 3$ concentrations decrease during the 4-
days PTD in sheep; $b$ ) the increase in serum $T 3$ and fall in $T 4$ and $\mathrm{rT3}$ before birth probably are due to augmented T4 to T3 conversion; c) the perinatal T3 surge has 2 phases: a slow prenatal phase and an abrupt postnatal phase. The prenatal phase may be cortisol induced.

\section{9}

ECHOCARDIOGRAPHIC STUDIES OF THE DEVELOPING HUMA FETUS. Charles S. Kleinman, John C. Hobbins, Diana L Creighton, and Norman S. Talner," Yale Univ. Sch. of Med., Depts. of Peds, \& Obs. and Gyn., New Haven, CT. In utero M-mode echocardiographic (echo) studies were used to evaluate the cardiac anatomy and function of 30 human fetuses be tween 25 and 41 weeks gestation. Real-time scanning of the mater ral abdomen, performed during routine evaluation of "high-risk" pregnancies, was used to locate the position of the fetal heart. Mitral-aortic and septal-aortic fibrous continuity and the spatial relationships of cardiac valves could be demonstrated in all Ventricular ejection times could be measured directly from semilunar valve echograms. Left ventricular (LV) ejection times were equal to ejection times in premature infants born at simila gestational ages $(208+30 \mathrm{msec})$. In 3 fetuses in which LV and right ventricular (RVT ejection times could be measured simultaneously these values were equal. Abnormal mitral valve motion enabled us to diagnose congenital complete heart block in the bradycardic 28 week fetus of a mother suspected of having systemic lupus erythematosis. The ventricular septum and LV posterior wall were visualized in 19 of the 30 fetuses. Septal motion was "normal" in 4 and "paradoxical" in 15 ("type A" in 11 "type B" in 4). The latter finding suggests that human fetal flor patterns are characterized by a "dominant" RV, and is consistent with in utero flow data in fetal lambs showing $2 / 3$ of combined ventricular output to be ejected by the RV. In utero echo studie are feasible and offer a noninvasive method of physiologic and anatomic evaluation of the heart of the human fetus.
Departments of Pediatrics and Medicine, Houston

Myocardial cell division continues postnatally for 15-21 days in the newborn rat but the mechanism by which hyperplasia ceases is unknown. It was the purpose of this study to investigate the role of sympathetic nerve (SN) ingrowth on myocardial cell division in the newborn rat ventricle. Chemical sympathectomy was induced by the subcutaneous administration of $50-100 \mathrm{\mu g} / \mathrm{g}$ bodyweight of 6-OH-Dopamine (6-OHD) to each of $226 \mathrm{Holtzman}$ newborn rat pups daily for the first seven days of life. Saline $(0.1 \mathrm{ml}$ was injected into 227 control rat pups. Effective sympathectomy was verified by identifying a reduction in ventricular myocardial norepinephrine levels to $20.60 \%+2.32$ SEM of control at $26-$ 38 days post-birth. Activity of DNA polymerase (DNA-P) in the ventricular homogenate was used to indicate the extent of myocardial cell division. DNA-P was assayed by measuring the initial rate of incorporation of deoxy-methyl $3_{H}$ thymine triphosphate (3HdTP) into an acid-insoluble product (per mg protein) using heat denatured DNA as the primer template.

Results were expressed as percent of control. DNA-P was increased in the sympathectomized pups older than 10 days. The gradually decreased but remained elevated at 26-38 days (161.57\% +18.9 of control). Therefore, in newborn rats, the norma? decrease in myocardial cell hyperplasia appears in part due to myocardial ingrowth of the sympathetic nerves.
191 EPIDERMAL GROITH FACTOR (EGF) EXTEIIDS LIFE SPAII OF NORMAL HUMAST FIBROBLASTS IN CULTURE. Roger L. Ladda, Terilee Gianopoulos, Lynn McCormick. Penn

Coll lied, M. S. Hershey Med Ctr, Dept Ped, hershey, PA. Normal human fibroblast cultures derived from newborn foresk
F) have a limited in vitro life span of $50 \pm 10$ cumulative population doublings (CPD). Adding EGF $(25 \mathrm{ng} / \mathrm{ml})$ to cultures at different stages of in vitro aging increased the survival of individual strains by as much as $25 \%$ (10-15 CPD). In early single passages, EGF produced a nearly 2 fold greater cell density over control cultures. With increasing CPD, HF progressively slowed decreased EGF sensitivity as reflected by decreased stimulation of cells to initiate DNA synthesis and decline in saturation density of EGF treated cultures. Cell density was similar in control and EGF cultures during the final $4-6$ CPD. 1 greater CPD than those exposed to EGF at later stages. Intermittent or discontinuous EGF exposure from early passages produced maximum CPD. Removal of EGF from cultures after early continuous exposure did not abolish the expanded culture survival. After control HF reached about $80 \%$ of expected CPD, exposure to EGF did not significantly extend life span of the cultures. Colony size distribution was determined during early, middle and late passages of strains with/without EGF exposure. In each strain regardless of CPD, EGF significantly increased the size distribution curve of derived colonies. Thus, EGF enlanced the survival of cells in subculture and prolonged their proliferativ activity significantly beyond control cultures.

192 DECREASED SURVIVAL AND ALTERED MEMBRANE PROPERTIES OF RED BLOOD CELLS (RBC) IN THE NEWBORN RAT. Stephen A. Landaw (Spon. by Frank A. Oski), SUNY-Upstate Medical Center \&VA Hospital, Depts. of Medicine \& Radiol., Syracuse, NY.

Decreased survival has been noted for RBC of newborn man and rat(Ped.Res.11:1155,1977). The present studies investigate the possibility that decreased survival is due to an altered RBC membrane. Osmotic fragility of newborn(NB) rat $\mathrm{RBC}$ was increased ( $29 \%$ 1ysis in $0.5 \% \mathrm{NaCl}$; adult $\mathrm{RBC}: 6 \%)$, increasing to $92 \%$ following $1 \mathrm{hr}$ incubation at 200 in $\mathrm{pH} 9.2$ borate buffer (adult RBC: no change). Filtration half-time of RBC suspensions was prolonged (NB:40 min; adult:2-3 min) and returned to normal with advancing age ( $16 \mathrm{~min}$ at 6 days, $5 \mathrm{~min}$ at 12 days, $3 \mathrm{~min}$ at 26 days). Splenic uptake at $24 \mathrm{hr}$ was increased 15 -fold \& hepatic uptake increase 3-fold for ${ }^{51} \mathrm{Cr}$-labeled NB RBC as compared to adult RBC. Following treatment with the cross-linking agent dimethyladipimidate (DMA, 2-5mM, pH 9.2), survival of $51 \mathrm{Cr}$-1abeled adult $\mathrm{RBC}$ was slight1 y reduced from $100 \& 92 \%$ at $1 \& 24 \mathrm{hr}$ to $94 \$ 76 \%$. DMA $(2-5 \mathrm{mM})$ caused marked further reduction in survival of NB RBC from $64 \& 16 \%$ at 1 $\$ 24 \mathrm{hr}$ to $10 \& 3 \%$. Following incubation of intact RBC with glucose, electrophoresis of RBC membrane proteins yielded a pattern of
high molecular weight complexes(HMW) for NB, but not for adult, high molecular weight complexes(HMWC) for NB, but not for adult,
RBC. These results suggest an unstable RBC membrane in the newRBC. These results suggest an unstable $R B C$ membrane in the new-
born rat, leading to altered osmotic fragility, reduced deformability, splenic trapping, and reduced survival. Preferential hemolysis of DMA-treated $N B$ rat $R B C$ and HMWC formation suggest that an altered state of aggregation of membrane proteins may underlie these abnormalities. 